\title{
The Academic Success of Boys and Girls as an Identity Issue in Gender Relations: When the most threatened is not the one expected
}

Sicard, Alyson ${ }^{\mathrm{a}^{*}}$, Martinot, Delphine $\mathrm{a}^{\mathrm{a}^{*}}$ and Toczek, Marie-Christine ${ }^{\mathrm{b}}$

${ }^{a}$ LAPSCO, Université Clermont Auvergne, Clermont-Ferrand, France; ${ }^{b}$ Laboratoire Acté, Université Clermont Auvergne, Clermont-Ferrand, France

*Corresponding authors: Alyson Sicard (alyson.sicard@uca.fr) and Delphine Martinot (delphine.martinot@uca.fr)

This is an accepted manuscript of an article published online in The Journal of Social Psychology on April 13 $3^{\text {th }}, 2021$ (https://doi.org/10.1080/00224545.2021.1902921). 


\begin{abstract}
The present research aims to determine whether girls' higher academic achievement, which should grant them a higher academic status than boys, could prevent them from experiencing social-identity threat on this dimension. Because they fear situations questioning their superiority, we argue that an unfavourable intergroup comparison would be more threatening for the high-status, rather than low-status, group on the dimension of academic achievement. Two studies were conducted respectively in high school, where girls should represent the high-status group (Study 1), and middle school, where students might perceive their own group as the high-status group (Study 2). Although both middle-school and high-school students perceived girls as the high-status group, they appraised the outgroup superiority differently. Indeed, it had more impact on girls' perceived threat and boys' perceived challenge in high school (Study 1), but not in middle school (Study 2). The results, however, did not show significant impact of context on performance.
\end{abstract}

Keywords: social identity, threat, gender, challenge, academic achievement 
Extensive literature is available regarding social-identity threat related to gender in the school context. For many years, research has particularly demonstrated the deleterious impact of gender stereotypes on girls' mathematic performance (e.g., Good, Aronson, \& Harder, 2008; Huguet \& Régner, 2007; Neuville \& Croizet, 2007; Regner, Steele, Ambady, Thinus-Blanc, \& Huguet, 2014; Spencer, Steele, \& Quinn, 1999; Tomasetto, Alparone, \& Cadinu, 2011). Yet recent studies have focused on boys' bad reputation at school, showing for instance the negative impact of gender stereotypes on boys' reading performance (Pansu et al., 2016). More importantly, research has suggested that girls' academic superiority leads to the construction of a general academic stereotype favoring their group, which can threaten boys' social identity and affect their performance (Hartley \& Sutton, 2013; Latsch \& Hannover, 2014). Indeed, numerous surveys and studies have shown that boys are less academically successful than girls are as they tend to have lower grades and are less likely to pursue higher education (EURYDICE, 2010; Fiske, 2012; OECD, 2015; Voyer \& Voyer, 2014). Insofar as the reputation of one's group and its relative position compared to outgroups is known to influence students' beliefs and performance (e.g., Ambady et al., 2001), such findings raise the question of whether girls' favorable position on the dimension of academic achievement could now prevent them from experiencing threat on this dimension. However, few studies have actually measured individuals' feeling of social identity threat, whether it is related to gender or not. Instead, the feeling of threat is often inferred from the observed consequences of a threatening situation, such as lowered performance (e.g., Berjot et al., 2012; Spencer et al., 2016; Steele et al., 2002). Therefore, the purpose of the present research is to better understand how an academic context threatening social identity affects both the perceived feeling of threat and performance of male and female middle- and high-school students. Contrary to previous studies on gender issues, these experiments do not focus on the general concept of gender stereotypes, but rather aim to introduce a more specific, yet unexplored, variable — namely, perceived 
academic status of boys and girls - as a factor likely to moderate the consequences of potentially threatening intergroup comparison contexts.

\section{Gender Status in Academic Contexts}

Tajfel and Turner (1979) defined status as the outcome of social comparison, which reflects a group's relative position on some evaluative dimension of comparison. Similarly, Sachdev and Bourhis (1987) considered status as "the relative position of groups on valued dimensions of comparison such as educational achievement or occupation". In the academic context, one (if not the most) relevant dimension of comparison is academic achievement. Indeed, most students enjoy receiving good grades and think that trying hard at school will help them get into a good college and get a good job (OECD, 2013). Although related, the concepts of academic status and academic stereotypes are distinct. The former aims to be more specific than the latter. Stereotypes are defined as "people's beliefs about the attributes, typically personality traits, that define a group" (Yzerbyt, 2016). Conversely, status focuses on an active comparison between groups. It does not address the characteristics associated with a particular group, but rather its relative position on an important dimension of comparison. For instance, believing that men have great leadership, which refers to gender stereotypes, is different than believing they are better managers than women (which relates specifically to occupational status). The stereotype content model (Fiske et al., 2002) considers group status as a predictor of stereotype content, and more particularly the dimension of competence (Cuddy et al., 2008). However, authors' conceptualization of group status differs from the one used in the present research, as they refer to the global social structure, rather than a domain-specific indicator (Fiske et al., 2002). Nevertheless, through the traits ascribed to different groups, stereotypes often provide information regarding which group is expected to have the highest status in a given domain. The literature on the "think manager-think male effect" has, for example, shown than men are thought to possess all the characteristics that would make them better managers than women 
(Koenig et al., 2011). Thus, gender stereotypes regarding the academic domain could provide information on students' beliefs regarding boys' and girls' academic status.

Numerous studies have pointed out the existence of a gender gap in academic achievement in favor of girls, who tend to earn better grades than boys (OECD, 2015; Pomerantz et al., 2002; Voyer \& Voyer, 2014), are less likely to repeat a grade (EURYDICE, 2010; OECD, 2015), and are more likely to enter and graduate from higher education than boys (European Institute for Gender Equality, 2017; EURYDICE, 2010; Fiske, 2012). In France, where the present studies were conducted, girls are more successful than boys at all national secondary education exams (DEPP, 2020). Given the proposed definition of context-specific group status (Sachdev \& Bourhis, 1987; Tajfel \& Turner, 1979), girls' higher academic achievement should provide them with a higher academic status than boys. Some studies have suggested that students are aware of this gender gap in academic achievement and the associated gender groups' status. For instance, primary school students appear to believe and think that adults believe that girls are academically superior to boys (Hartley \& Sutton, 2013). Similarly, older students (ninth graders) give a more negative description of boys than girls in the school context (Latsch \& Hannover, 2014). Regarding specific academic domains, Martinot et al. (2012) showed that students believe that girls are better than boys in reading and, contrary to traditional gender stereotypes regarding adults, as good as them in mathematics.

Despite Hartley and Sutton's (2013) demonstration of primary students' beliefs in girls' academic superiority, several studies have suggested that young people only have a limited awareness of gender dynamics. Indeed, children and early adolescents appear to be influenced by a strong ingroup favoritism bias towards their gender group (Maccoby, 1987; Powlishta, 1995; Robnett \& Susskind, 2010; Susskind \& Hodges, 2007; Verkuyten \& Thijs, 2001; Yee \& Brown, 1994). In line with this observation, some studies have suggested that young students try to establish a positive distinction for their gender group in the academic context (e.g., 
Heyman \& Legare, 2004; Martinot \& Désert, 2007; Nowicki \& Lopata, 2015; Passolunghi et al., 2014). Kurtz-Costes et al. (2014), for instance, showed that fourth and sixth graders exhibited more ingroup bias than eighth graders regarding academic stereotypes in that they were more likely to report verbal, math, and science characteristics favoring their gender group. Thus, the literature suggests that high-school students might show less ingroup bias and would be more aware of girls' academic superiority than middle-school students. Our first hypothesis is therefore that, in accordance with the observed gender gap in achievement, high-school students will attribute a higher academic status to girls on the dimension of academic achievement (Study 1). On the contrary, we expect middle-school students to attribute a higher academic status to their own gender group, as girls will perceive girls to have a higher academic status than boys, whereas boys will report boys' academic status as higher than that of girls (Study 2). By examining the question of the status ascribed to each gender group, this research aims to test whether gender group status influences boys' and girls' reactions to an academic comparison context threatening their social identity. More specifically, we test whether belonging to a high-status group on the dimension of academic achievement could prevent students from experiencing threat on this dimension. An academic context of comparison between gender groups is specifically relevant to generate feelings of social identity threat due to the evaluative pressure attached to academic achievement.

\section{Threat and Challenge to Gender Identity as a Function of Group Status}

Threat and challenge are considered in the literature as the two main types of cognitive appraisals of a stressful situation (Blascovich, 2008; Lazarus \& Folkman, 1984). According to Lazarus and Folkman (1984), threat appraisal refers to the anticipation of negative consequences whereas challenge appraisal focuses on potential gain or growth from the stressful event. Recently, Berjot and Gillet (2011) developed the Model of Stress and Coping with Stigma and Identity Threats, in which they applied the concept of cognitive appraisal to 
stressful situations related to one's identity and examined the antecedents, appraisals, and coping associated with identity-relevant situations. According to this model, the appraisal of a situation as a threat or a challenge to one's personal or social identity depends on personal characteristics (e.g., coping styles, ideology), the characteristics of the stigma (visibility and controllability), and situational characteristics (social context, social support, and situational indices). As previously mentioned, gender-related threats in the academic context have been extensively studied as part of research on the stereotype threat phenomenon (Pansu et al., 2016; Regner et al., 2014). Rather than examining the consequences of stereotypical expectations, the present research focuses on the influence of group status on students' experience of socialidentity threat (related to their gender) in academic context.

Several studies - most of them using physiological indicators of threat and challengehave demonstrated that both high- and low-status groups can experience social-identity threat. Threat, however, emerges in different contexts. For instance, low-status group members report more threat when the position of their group is described as legitimate rather than illegitimate, whereas high-status group members perceive status differences as more threatening when presented as illegitimate rather than legitimate (Scheepers, 2017). Contrary to low-status groups whose primary source of threat appears to be the status quo, high-status groups are more likely to be threatened by the possibility of change in the status quo (Scheepers et al., 2009; Scheepers \& Ellemers, 2005). Indeed, given their privileged position within the system (e.g., prestige, social respect, resources), high-status groups have more to lose from a change in group hierarchy compared to low-status groups. Consistent with this idea, some studies have demonstrated that high-status groups are threatened by diversity (Dover et al., 2016; Ellemers \& Bos, 1998; Major et al., 2018). Similarly, Scheepers et al. (2009) showed that men display higher pulse pressure (a physiological indicator of threat) than women when discussing a progressive (gender-related) topic in an intergroup context. These findings therefore suggest 
that, although for different reasons, both the high- and low-status gender groups on the dimension of academic achievement might feel more social-identity threat in a context of outgroup academic superiority than in a context of ingroup superiority. Students of the highstatus gender group would perceive the induced academic superiority of the low-status outgroup as a threat for their privileged position at school and/or as evidence of the illegitimacy of their position, whereas students of the low-status gender group could perceive the induced academic superiority of the high-status outgroup as a threat insofar it reinforces and legitimize their inferior position.

However, in their research, Vick et al. (2008) showed that men were more physiologically reactive than women, as they demonstrated stronger patterns of threat and challenge under similar conditions. Thus, although low-status group members experienced more threatening situations, high-status group members could perceive the threats as more salient. Supporting this assumption, research on attribution to discrimination has shown that high-status group members are more likely to be vigilant in their perceptions of prejudice against them, in contrast to low-status groups members who minimize it (Branscombe et al., 1999; Ruggiero \& Major, 1998; Ruggiero \& Taylor, 1997; Schmitt \& Branscombe, 2002). Like prejudice, high-status groups might be more likely than low-status groups to identify socialidentity threat, even though they are less susceptible to cope with such negative experience. Consequently, the effect of intergroup comparison context described above might be moderated by the group status. Members from both the high- and low-status gender group would report more social-identity threat when exposed to the outgroup's academic superiority than in a context of ingroup academic superiority, but this effect might be stronger for the high-status gender group.

\section{Impact of Threat and Challenge on Performance}


Feeling that one's identity is threatened is likely to have an impact on performance. Indeed, in a school context, perceiving an evaluative situation as a threat tends to have a deleterious effect on academic performance (Chalabaev et al., 2009; Seery et al., 2010; Skinner \& Brewer, 2002). Intergroup Threat Theory (Stephan et al., 2009) suggests that, although lowstatus groups are more likely than high-status groups to experience social-identity threats, highstatus groups might react more strongly to threat. Indeed, Autin et al. (2014) demonstrated that social-identity threat can have a greater impact on the performance of high-status group members (in the context of their experiment, men) than on that of low-status group member (i.e., women). The authors conducted a series of study that is, to our knowledge, one of the few which intend to threaten the performance of both high- and low-status group. To do so, they manipulated selection policies (to nominate a manager), making them more or less threatening for men and women. Their results showed that men performed less well in an environment threatening their gender identity (i.e., threatening policy based on diversity) than in a less threatening environment (policy based on merit). Women's performance, in contrast, was not significantly affected by context (Autin et al., 2014). Group status therefore seems to moderate the impact of social identity threat on performance. More precisely, we can hypothesize that the detrimental effect of gender-identity threat would be stronger among the high-status gender group in academic context.

Because threat is negatively related to academic performance (Chalabaev et al., 2009; Seery et al., 2010; Skinner \& Brewer, 2002), we expect that participants will have the worse performance in the most-threatening context. Both high- and low-status gender groups might therefore have poorer performance in an outgroup superiority context compared to an ingroup superiority context. However, the effect is hypothesized to be stronger for the high-status gender group. The present studies will test and confront two explanatory processes to account for the stronger impact of intergroup comparison context on the performance of members of 
the high-status gender group (compared to low-status gender group members). As illustrated in Figure 1, differences in the effect of the intergroup comparison context on students' performance depending on their group status might be related to either differences in perceived identity threat (Model A) or to differences in reaction to this threat (Model B). These explanatory processes refer to different moderated mediation models. The first model, Model A, is based on the hypothesis of a main effect of the intergroup comparison context on students' perceived social-identity threat (see Figure 1). In other words, we expect that members from both the high- and low-status gender groups will report more social-identity threat when exposed to the academic superiority of the outgroup compared to the academic superiority of the ingroup. The academic status of gender groups will then moderate the effect of perceived social-identity threat on performance as, based on Intergroup Threat Theory (Stephan et al., 2009), this threat might have a greater impact on members of the high-status (vs low-status) gender group. Both low- and high-status group members would perform less well in the outgroup academic superiority context compared to a context of ingroup academic superiority, but these differences would be more important among members of the high-status group. The second model, Model B, is based on our alternative hypothesis regarding perceived identity threat, in which we expect the academic status of boys and girls to be a moderator of the effect of intergroup comparison context on perceived identity threat. More precisely, we hypothesize that, compared to students from the low-status gender group, students in the high-status gender group will report stronger social identity threat in an academic context emphasizing the outgroup's superiority than in a context in which the ingroup's superiority is highlighted. The greater the threat, the lower the performance will be. In this alternative model, the intergroup comparison context is expected to have a stronger impact on the performance of high-status students - not because they react more strongly to threat, but because they will feel more identity threat (see Figure 1). 
Because few studies have addressed the challenge appraisal, particularly in identityrelevant situations, we also examine the feeling of challenge related to male and female students' social identity, albeit in an exploratory way. As we hope to achieve a more complete understanding of their appraisal of potentially stressful academic contexts, we did not develop hypotheses on this measure.

[FIGURE 1 NEAR HERE]

\section{Identity-threat Feeling and Performance as a Function of Education Level: Middle- vs high-school students}

As previously argued, we hypothesized that the academic status ascribed to male and female students will evolve between middle school and high school. In high school, students would be aware of the higher academic achievement of girls (compared to boys); thus, we expect female students to be perceived as the high-status group. Both alternative moderated mediation models (Model A and Model B) presented above predict that both female and male high-school students would perform less well in an unfavorable intergroup comparison context emphasizing the outgroup's academic achievement as opposed to a context highlighting the ingroup's achievement, with a more pronounced effect of context among female students as the highstatus group. This stronger effect of intergroup comparison context on girls' performance could either be related to a stronger impact of perceived threat on girls' rather than boys' performance, despite the similar perception of threat in response to an outgroup superiority context (Model A), or explained by higher perceived threat among girls compared to boys when exposed to the higher achievement of the outgroup (Model B). Study 1 aims to test both processes.

However, in the middle-school context, we expect an ingroup favoritism bias among both boys and girls, who would consider their own gender group as the high-status group. Both theoretical models (Model A and Model B) therefore lead to the same operational hypothesis, which corresponds to a main effect of the intergroup comparison context. Insofar as they 
consider their own group as the high-status group, both female and male middle-school students should report more threat to their social identity and then have poorer performance in an academic context emphasizing the outgroup's academic achievement than in a context in which the ingroup's superiority is highlighted. Study 2 tests this hypothesis.

Exploring our hypotheses through two different studies, each corresponding to a level of education (high school and middle school), allows for a better distinction between the role of the academic status and the role of gender. Indeed, status, even context-specific status, is difficult to distinguish from some social group membership as the two factors are often confounded (Fiske et al., 2016). These social group memberships include, but are not limited to, gender. Conducting strictly similar studies in two academic backgrounds supposed to be associated with different (academic) status dynamics related to gender should help distinguish the effects of gender from those of academic status. If we obtain similar effects of context in the two studies, even when students ascribe different academic status to boys and girls, we will able to conclude to a gender effect. However, if the effects instead differ as a function of the education level, they are more likely to be associated with group status dynamics. Indeed, our hypotheses are that differences in the academic status attributed to female and male students, not gender itself, should lead to differences in feeling of social identity threat and performance. These differences in the academic status attributed to female and male students are expected to depend on education level. Thus, Study 1 is conducted in high school, an academic context in which girls should be considered as the high-status group on the dimension of academic achievement, and Study 2 is conducted in middle school, where both boys and girls might perceive their gender group as the high-status group.

\section{Study 1}


Study 1 sought to understand female and male high-school students' appraisal of two genderrelevant comparison contexts and their impact on performance at a level of education where girls are expected to represent the high-status group on the dimension of academic achievement. According to Model A, both female and male high-school students will perceive an academic context highlighting the outgroup's academic achievement as more threatening to their social identity than a context in which the ingroup's superiority is emphasized. Then, perceived social identity threat would have a greater impact on female students' (rather than male students') performance. An alternative hypothesis, presented in Model B, is that female and male highschool students actually differ in their appraisal of the situation. Female students would feel more threatened in an academic context emphasizing the outgroup's academic achievement compared to a context of ingroup academic superiority, whereas such intergroup comparison contexts would have less impact on male students' perceived social identity threat. As identity threat is expected to have a negative impact on performance, the impact of the intergroup comparison context should be stronger for girls' performance. Finally, as a stressful situation can be appraised as a threat but also as a challenge, we decided to include, on an exploratory basis, a measure of challenge to social identity (Berjot et al., 2012). Study 1, its hypotheses, its method, and its analysis plan have been preregistered on Open Science Framework (https://osf.io/7tnau/?view_only=6eae98d63ede481fb63b7d926e174dc4).

\section{Method}

\section{Participants}

A priori power analysis, based on the effect size obtained in a previous study (presented in the first author's thesis manuscript), suggested that a sample of at least 248 participants was necessary to replicate an interaction effect whose effect size was $\mathrm{f}^{2}=0.032$ with $1-\beta=.80$ 
power ${ }^{1}$. As the yellow vest movement (which also affected high schools) interfered with our data collection, the number of students recruited was lower than expected. Ultimately, 204 tenth-grade students from two different high schools (one private school and one public school) located in a French provincial town volunteered to take part in this study. Authorizations from parents and school directors, as well as ethical approvals from the university ethics committee (\# IRB00011540-2018-09), were provided.

We excluded four participants from the sample before conducting any analysis (three for issues related to their gender identification and one because s.he did not properly complete the questionnaire) and four additional participants following the analysis of the manipulation check measure (see Results). Thus, our final sample comprises 196 students: 81 girls and 115 boys, whose average age was 15.04 years old $(S D=0.42)$.

\section{Study Design}

This study is a quasi-experimental study with male and female students randomly assigned to one of the two conditions of academic context. Academic context was manipulated so that participants thought their ingroup (boys or girls) was either more, or less, academically successful than the outgroup, in that it outperformed or was outperformed by the other group at an important national exam. The study design is therefore a 2 (gender: boys vs. girls) x 2 (context: outgroup superiority vs. ingroup superiority) between-participants factorial design.

\section{Procedure}

In their regular classroom, along with their classmates, participants completed a paper-andpencil questionnaire. The study was presented as research dealing with the results of the 2018 end-of-secondary-education diploma (i.e., baccalauréat). First, participants assessed boys' and

\footnotetext{
${ }^{1}$ The analysis we conducted for the preregistration suggested that a sample of 195 participants. However, following the preregistration, we noticed an error in the calculation of the sample size which was computed for a unilateral test instead of a bilateral test.
} 
girls' academic status in high school, based on their respective academic achievement (see the Measures section). They were then exposed to what was presented as "real information" regarding gender differences in academic achievement, which actually corresponded to our manipulation of the academic context. At this point, participants were randomly assigned to either the outgroup superiority condition or the ingroup superiority condition. In the outgroup superiority context, participants reviewed graphs depicting the outgroup as outperforming the ingroup for the 2018 baccalaureate. In other words, boys were confronted to graphs showing that girls outperformed boys while girls received graphs showing that boys outperformed girls. In the ingroup superiority context, graphs showed that the ingroup outperformed the outgroup for the 2018 baccalaureate. Thus, boys [girls] received graphs that showed that they outperformed girls [boys]. After reviewing the graphs and completing our manipulation check, participants completed the threat and challenge to gender identity scales to assess their perception of the induced intergroup comparison context and then took a five-minute test on general knowledge. Finally, they filled out socio-demographic measures such as their gender, their parents' highest degree (as an objective indicator of socio-economic status), their grades, and their subjective socio-economic status (SES; Adler et al., 2000). The experimenter debriefed the participants to reveal the fictitious nature of the information given by the graphs and gave them some time to discuss the experiment.

\section{Measures}

Perceived academic status was assessed using a measure derived from Sweeting et al.'s (2011) measure of scholastic status. Students were asked to position boys and girls on a ladder representing high-school students, where the top of the ladder represented the most academically successful students, described as those with the best grades and the best results on exams. Participants' scores (from 1 to 10) corresponded to the rung of the ladder on which 
they positioned each group (boys and girls). Higher rungs meant higher scores and thus higher perceived academic status.

A manipulation check was included in the questionnaire to ensure that all participants read and understood the information presented in the graphs. Students had to fill in the blanks in a short text that described the academic context induced in the graphs. We considered that participants had assimilated the information contained in the graph when they were able to indicate which group was portrayed as the most academically successful.

We measured how participants appraised the induced academic context in terms of threat and challenge to their gender identity using two (independent) subscales of the Primary Appraisal of Identity Threat scale (Berjot et al., 2012). Threat to gender identity was measured using the five items of the corresponding threat to social identity subscale $(\alpha=.83)$. We reworded the items so that they directly referred to students' gender identity (e.g., "When I read the information about the baccalaureate results, I had the feeling that girls [boys] were insulted."). One of the items ("When I read the information about the baccalaureate results, it gave me the feeling of being judged as a typical girl [boy]") was excluded from the analysis due to its low correlation with the rest of the items and its lack of fit on the threat to gender identity factor ${ }^{2}$. To assess challenge to gender identity, we used the three items of the challenge to social identity subscale that were adapted to the requirement of this study (e.g., "When I read the information about the baccalaureate results, it gave me the will to fight to defend my female [male] identity"; $\alpha=.87$ ). The response scale, depicted on a barometer, ranged from 1 (strongly disagree) to 7 (strongly agree).

Students' performance was assessed using the Information subtest from the Wechsler Adult Intelligence Scale (WAIS-IV), which comprised 24 general knowledge questions. The

\footnotetext{
${ }^{2}$ The factor loading of the item was 0.27 and its mean correlations with the other items of the scale was $\mathrm{r}=0.26$.
} 
WAIS-IV was designed for individuals aged 16 or older. Although most of our participants were expected to be between 15 and 16 years old, we decided to use this version of the test (instead of the children's version) to avoid a ceiling effect. Students had five minutes to complete the test and answer as many questions as possible. Two independent judges, blind to participants' gender or experimental condition, corrected the test based on the recommendations of the WAIS-IV. Any differences in correction between judges were then discussed (interrater reliability, $r=0.98)$.

\section{Results}

Means, standard deviations and correlations between variables are presented in Table 1.

[TABLE 1 NEAR HERE]

\section{Perceived academic status}

To ensure that students perceived girls as the high-status group in high school, we conducted a repeated-measure ANOVA with the target group (boys and girls) as a within-participant factor and the participants' gender (girls vs. boys) as a between-participants factor. The analysis revealed a significant main effect of the target group, $F(1,193)=48.71, p<.001, \eta_{p}^{2}=.322$. Consistent with our hypothesis, students attributed a higher academic status to girls $(M=8.09$, $S E=0.08)$ than to boys $(M=7.37, S E=0.02)$ in high school. This effect was not moderated by participants' gender, $F<1$, ns.

\section{Manipulation check}

As previously mentioned, we included a manipulation check to ensure that participants carefully read and understood the information regarding boys' and girls' academic achievement. Students had to fill in the blanks in a short text summarizing the presented information. Four participants were excluded from analysis, as their completion of the text was not consistent with the information to which they were exposed. 


\section{Threat and challenge to social (gender) identity}

We regressed perceived threat and challenge to gender identity on academic context (coded 0.5 for outgroup superiority, 0.5 for ingroup superiority), gender ( -0.5 for boys, 0.5 for girls), and their interaction term. The regression analyses were conducted using the bootstrap approach based on 5,000 bootstrap replicates.

Regarding threat to gender identity, the analysis revealed a main effect of context, $B=$ $1.00, S E=0.17, \mathrm{BCa} 95 \% \mathrm{CI}[0.67,1.34], p<.001$. Participants exposed to the outgroup's academic superiority $(M=2.41, S D=1.48)$ reported more threat to their gender identity than those exposed to the ingroup's superiority $(M=1.48, S D=0.72)$. The main effect of participants' gender was not significant, $B=0.18, S E=0.17$, BCa 95\% CI $[-0.15,0.52], p=$ .299, ns. Although the interaction between academic context and gender did not reach significance $(B=0.56, S E=0.34, \mathrm{BCa} 95 \%$ CI $[-0.11,1.24], p=.105)$, academic context seemed to have a stronger impact on girls' perceived threat, $B=1.28, S E=0.26, \mathrm{BCa} 95 \% \mathrm{CI}$ $[0.78,1.81], p<.001$, than on boys' perception of gender identity threat, $B=0.72, S E=0.22$, BCa 95\% CI $[0.28,1.16], p=.001$ (see Figure 2).

We then analyzed students' perception of challenge to their gender identity. The results showed a significant main effect of gender, $B=0.72, S E=0.29$, BCa $95 \% \mathrm{CI}[0.20,1.25], p=$ .008 . Indeed, girls $(M=4.28, S D=1.91)$ felt more challenge to their gender identity than boys $(M=3.52, S D=1.92)$. There was also a main effect of context in that students reported more challenge when they were confronted with the outgroup's academic superiority $(M=4.36, S D$ $=1.84)$ compared to the ingroup's superiority $(M=3.33, S D=1.91), B=0.90, S E=0.26, \mathrm{BCa}$ $95 \% \mathrm{CI}[0.38,1.42], p=.001$. Moreover, the analysis revealed a significant interaction between the two predictors, $B=-1.32, S E=0.53$, BCa 95\% CI $[-2.39,-0.28], p=.014$. Contrary to our hypothesis, simple effects indicated that boys perceived a greater challenge to their gender identity in a context in which the outgroup's, rather than the ingroup's, academic superiority 
was highlighted $(B=1.56, S E=0.32, \mathrm{BCa} 95 \% \mathrm{CI}[0.91,2.19], p<.001)$, whereas the academic context did not have a significant impact on girls' perceived challenge $(p>.10, n s)$. Regardless of the context, girls reported relatively high levels of challenge to their gender identity (see Figure 2).

\section{[FIGURE 2 NEAR HERE]}

\section{Performance}

We tested the same regression model on performance. The analysis revealed a main effect of gender, $B=-1.76, S E=0.39$, BCa 95\% CI [-2.51, -1.01$], p<.001$. Boys $(M=11.18, S D=3.04)$ outperformed girls $(M=9.41, S D=2.49)$ on the general knowledge test. This effect of gender remained significant when controlling for participants' grade average. The analysis revealed no significant main or interaction effect of context on performance, $p>.10, n s$.

As indicated in the pre-registration, we conducted complementary analyses to control for the effects of students' SES and type of school. These analyses revealed similar effects of our predictors (gender, context, and their interaction) on the three outcomes, which supported our choice of a parsimonious model.

\section{Moderated mediation model and indirect effects}

Although previous analysis did not reveal a significant total effect of academic context on performance, we conducted a test of the indirect effects through perceived threat and challenge using the model 59 on the PROCESS macro (Hayes, 2013). Indeed, some authors argue that various factors (e.g., sample size, effect size) could lead to a significant indirect effect (often referred as $a \times b$ ) in the absence of a significant total effect of the predictor on the outcome (c') (Rucker et al., 2011). We therefore tested a moderated mediation model with the academic context as the predictor $(\mathrm{X})$, performance as the outcome $(\mathrm{Y})$, gender as the moderator (Mo) and threat to gender identity as the mediator (Me). Participants' grade average was included as a covariate. The results, which are presented in Table $2 \mathrm{a}$, revealed that the moderated mediation 
index $(\mathrm{B}=-0.13, \mathrm{SE}=0.32,95 \mathrm{CI} \%[-0.68,0.56])$, as well as the indirect effects of academic context on performance through perceived threat to gender identity for boys $(\mathrm{B}=0.10, \mathrm{SE}=$ $0.15,95 \mathrm{CI} \%[-0.22,0.41])$ and girls $(\mathrm{B}=-0.03, \mathrm{SE}=0.28,95 \mathrm{CI} \%[-0.52,0.58])$ were not significant. Indeed, perceived threat to gender identity did not have a significant effect on performance, $\mathrm{B}=0.05, \mathrm{SE}=0.16,95 \mathrm{CI} \%[-0.26,0.36], p=.740, n s$. Similar analysis were conducted with challenge to gender identity as the mediator, which also yielded non-significant results (see Table 2b).

[TABLES 2a and 2b NEAR HERE]

\section{Discussion}

The objective of Study 1 was to understand how students appraise different academic contexts comparing the achievement of gender groups and their impact on performance, according to the perception of the academic status of these groups. We hypothesized that, in the high school, girls would be perceived as the high-status group on the dimension of academic achievement. As expected, students attributed a higher status to girls than to boys on this dimension. These results are consistent with our hypothesis regarding gender dynamics in high school. Participants' gender did not moderate their perception of boys' and girls' academic status, suggesting that these results are not due to girls' ingroup favoritism bias, as both groups shared the same perception of academic status.

Study 1 also aimed to test two moderated mediation models in which a moderator (gender) might interfere in the effect of the mediator (social identity threat) on the outcome (performance) or on the effect of the predictor (intergroup comparison context) on the mediator (see Figure 1). Results showed that, in line with the predictions of Model B, the effect of the intergroup comparison context on students' appraisal is moderated by group status. Indeed, although both groups perceived the outgroup superiority context as more threatening than ingroup superiority, context tended to have a greater impact on the feeling of gender identity 
threat experienced by the high-status group (i.e., girls). Such a finding is consistent with research showing that, under a similar threatening condition, men (as the high-status group in this context) are more physiologically reactive than women (Vick et al., 2008). Yet, compared to the context of ingroup academic superiority, the academic context of outgroup superiority significantly affected boys', but not girls', perceived challenge. Regardless of the context, girls reported high levels of challenge to their gender identity. It would be interesting to examine whether these divergent effects of context on boys' and girls' cognitive appraisal were replicated in Study 2.

Both models hypothesized that, although boys and girls would have lower performance when confronted with an outgroup superiority context compared to ingroup superiority, this effect of the intergroup comparison context would be stronger for girls because of the high status assigned to their group. Contrary to this hypothesis, the results did not demonstrate a significant effect of intergroup comparison context on performance. However, boys appeared to outperform girls at the general knowledge test. Such differences were unexpected as we used a standardized subtest from the fourth version of the Weschler Adult Intelligence Scale (WAISIV). We chose the Information subtest because, although it is used to compute the verbal comprehension index, its items refer to different academic domains (e.g., science, literature, geography). However, several studies obtained similar results on this specific subtest, with men outperforming women (Colom et al., 2002; Daseking et al., 2017; Irwing, 2012; van der Sluis et al., 2006). The lack of context effect on performance might be partially related to the potentially biased nature of the test used to measure performance.

As a whole, the results of Study 1 suggest that the perceived academic status of boys and girls in the high-school context moderates students' appraisal of an intergroup comparison context as a threat or a challenge to their social (gender) identity. To confirm this effect of the 
perceived academic status, it is necessary to test it in an academic context in which gender status dynamics are likely to be different.

\section{Study 2}

Study 2 aimed to replicate Study 1 in a school environment associated with different gender status dynamics: middle school. As previously argued, students' awareness of girls' academic superiority would be less pronounced in middle school compared to high school. Indeed, several studies have shown that children and young adolescents are influenced by a strong favoritism bias in favor of their gender group (Maccoby, 1987; Powlishta, 1995; Robnett \& Susskind, 2010; Susskind \& Hodges, 2007; Verkuyten \& Thijs, 2001; Yee \& Brown, 1994). In the school context, they are more likely than older students to report stereotypical beliefs favoring their gender group (Heyman \& Legare, 2004; Kurtz-Costes et al., 2014; Martinot \& Désert, 2007; Passolunghi et al., 2014). For instance, students from fourth to sixth grade are likely to believe that their own gender group is the best in mathematics (Nowicki \& Lopata, 2015). Therefore, consistent with the idea of a strong ingroup favoritism bias, our first hypothesis is that middleschool students, both boys and girls, will attribute a higher academic status to their own gender group.

As Studies 1 and 2 were conducted simultaneously, our theoretical hypothesis regarding the impact of intergroup comparison context remains the same as Study 1. However, insofar as gender status dynamics should be different, the same theoretical hypothesis leads to a different operational prediction. Contrary to Study 1, the two moderated mediation models give similar predictions. More precisely, as middle-school students are expected to consider their own gender group as the high-status group, we hypothesize that both boys and girls will perform less well in an outgroup superiority context compared to an ingroup superiority context. We also postulate that students' increased perception of social-identity threat when confronting 
outgroup (as opposed to ingroup) academic superiority will account for this effect of intergroup comparison context on performance. Similar to Study 1, the hypothesis, protocol, and analysis plan of Study 2 were preregistered on the Open Science Framework (https://osf.io/nuk3f/?view_only=988fb1d1a56b45a19e2eed164a3560a9).

\section{Method}

\section{Participants}

Two hundred thirty-nine seventh-grade students were recruited from three different middle schools (including one private school) located in the same area as Study 1's high school. We excluded two participants from the sample before conducting any analysis (for issues related to their gender identification) and six additional participants following the analysis of the manipulation check measure (see Results). Our final sample therefore comprises 231 students, 132 girls and 99 boys, whose average age was 12.10 years old $(S D=0.47)$. Again, authorizations from parents and school directors, as well as ethical approvals from Clermont Auvergne University ethics committee (\# IRB00011540-2018-09), were provided.

\section{Procedure and Study Design}

The procedure and the study design were similar to those of Study 1. After assessing boys' and girls' academic status in middle school, participants were given graphs showing that either the ingroup (ingroup superiority context) or the outgroup (outgroup superiority context) was the most successful group at an important school exam. Instead of the baccalaureate, we decided to present middle-school students with information regarding an exam that was more relevant to them-namely, the French end-of-middle-school certificate (i.e., brevet des collèges). Participants then completed the primary cognitive appraisal scale and had five minutes to complete the general knowledge test. Finally, they filled in socio-demographic measures, such 
as their gender, their parents' highest degree, their grade average, and their subjective SES (Adler et al., 2000).

\section{Measures}

The different measures were similar to those presented in Study 1. We measured boys' and girls' perceived academic status in middle school using the same scales as in Study 1. Similarly, we used the same measure of perceived threat $(\alpha=.84)$ and challenge $(\alpha=.71)$ to gender identity. Finally, performance was assessed using the children's version of the information subtest from the fourth edition of the Weschler Intelligence Scale for Children (WISC-IV). This version was more suitable for a younger sample. The test comprised 24 questions, and participants' responses were corrected by the same judges as Study 1 .

\section{Results}

Means, standard deviations and correlations between variables are presented in Table 3.

\section{[TABLE 3 NEAR HERE]}

\section{Perceived academic status}

To examine middle-school students' perceptions of boys' and girls' academic status, we conducted a repeated-measure ANCOVA with the target group (boys and girls) as a withinparticipant factor and the participants' gender (girls vs. boys) as between-participant factor. The analysis only revealed a significant main effect of the target group, $F(1,227)=172.76, p<.001$, $\eta_{p}^{2}=.432$, as students attributed a higher academic status to girls $(M=8.01, S E=0.07)$ than to boys $(M=6.81, S E=0.09)$ in middle school. The interaction between the target group and participants' gender did not reach significance, $F(1,227)=2.68, p=.103$, $n s$, as male and female students both perceived girls' academic status as significantly higher than that of boys. Thus, contrary to our hypothesis, students' perception of boys' and girls' academic status did not vary depending on their gender. 


\section{Manipulation check}

The examination of students' completion of the manipulation check measure led us to exclude six participants from the subsequent analysis. For two participants, the completion of the text was not consistent with the information to which they were exposed. The remaining four students did not complete the text.

The following regression analyses are similar as those conducted in Study 1. Our regression model included three predictors: academic context (coded -0.5 for outgroup superiority, 0.5 for ingroup superiority), gender ( -0.5 for boys, 0.5 for girls), and their interaction term. The regression analyses were conducted using the bootstrap approach based on 5,000 bootstrap replicates.

\section{Perceived threat and challenge to social (gender) identity}

We first regressed our model on the perception of gender identity threat. The analysis revealed a main effect of the intergroup comparison context, $B=0.98, S E=0.20$, BCa 95\% CI [0.61, 1.37], $p<.001$. Results indicated that participants perceived the outgroup superiority context $(M=3.51, S D=1.68)$ as more threatening for their gender identity than the ingroup superiority context $(M=2.51, S D=1.23)$. There was also a main effect of gender, $B=0.44, S E=0.19$, BCa 95\% IC $[0.05,0.81], p=.028$, in that girls $(M=3.18, S D=1.58)$ reported more threat to their gender identity than boys $(M=2.74, S D=1.46)$. The interaction between participant's gender and intergroup comparison context did not appear to be significant or marginal, $B=$ $0.19, S E=0.39, \mathrm{BCa} 95 \% \mathrm{CI}[-0.57,0.93], p=.633, n s$.

Regarding challenge to gender identity, the analysis only revealed a main effect of the intergroup comparison context, $B=0.46, S E=0.22$, BCa 95\% CI $[0.04,0.88], p=.036$. Participants perceived the outgroup superiority context $(M=5.00, S D=1.64)$ as being more challenging to their gender identity than the ingroup superiority context $(M=4.52, S D=1.59)$. 
Neither the main effect of gender nor its interaction with intergroup context reached significance, $p_{\mathrm{s}}>.10, n s$.

\section{Performance}

The analysis revealed a main effect of gender, $B=-1.10, S E=0.39$, BCa 95\% CI [-1.86, -0.31$]$, $p=.006$. As in Study 1, boys $(M=11.88, S D=2.96)$ outperformed girls $(M=10.68, S D=2.95)$ on the general knowledge test. This effect of gender remained significant when controlling for participants' grade average. The analysis revealed no significant main or interaction effect of context on performance, $p>.10, n s$.

As in Study 1, we conducted complementary analyses to control for the effects of students' SES and type of school. These analyses revealed similar effects of our predictors (gender, context, and their interaction) on the three outcomes, which supported our choice of a parsimonious model.

\section{Moderated mediation model and indirect effects}

As in Study 1, we conducted additional analysis to investigate the indirect effect of academic context on performance through threat to gender identity, despite the absence of significant total effect. The results are presented in Table 4a. They revealed that the moderated mediation index $(\mathrm{B}=-0.39, \mathrm{SE}=0.27,95 \% \mathrm{CI}[-0.94,0.13])$, as well as the indirect effects of academic context on performance through perceived threat to gender identity for boys $(\mathrm{B}=$ $0.13, \mathrm{SE}=0.22,95 \mathrm{CI} \%[-0.29,0.59])$ and girls $(\mathrm{B}=-0.26, \mathrm{SE}=0.17,95 \mathrm{CI} \%[-0.63,0.05])$ were not significant. Again, threat to gender identity did not have a significant impact on performance, $\mathrm{B}=-0.98, \mathrm{SE}=0.13,95 \% \mathrm{CI}[-0.36,0.17], p=.463, n s$. Similar analysis were conducted with challenge to gender identity as the mediator, which also showed a nonsignificant moderated mediation, $\mathrm{B}=-0.18, \mathrm{SE}=0.16,95 \mathrm{CI} \%[-0.52,0.13]$ (see Table $4 \mathrm{~b}$ ). 


\section{Discussion}

Study 2 aimed to examine the consequences of two intergroup comparison contexts related to academic achievement on middle-school students' social-identity threat and performance as a function of gender groups' status. To distinguish the effect of status and the effect related to gender, we conducted this second study at a level of education supposedly associated with different gender status dynamics than those in action in Study 1. Based on literature showing a strong ingroup favoritism bias among children and young adolescents (e.g., Kurtz-Costes et al., 2014; Verkuyten \& Thijs, 2001), we predicted that middle-school boys and girls would believe that their own gender group had the highest academic status in middle school. Contrary to our hypothesis, the results showed that both middle-school male and female students attributed a higher academic status to girls compared to boys in middle school. Such a perception of gender inequalities in academic achievement is consistent with previous research suggesting the development of an academic gender stereotype in favor of girls from primary school (Hartley \& Sutton, 2013; Heyder \& Kessels, 2013; Latsch \& Hannover, 2014). However, contrary to Study 1, the intergroup comparison context has the same impact on the cognitive appraisal of female and male middle-school students. They perceived the outgroup superiority context in academic achievement as more threatening and challenging to their gender identity than the ingroup superiority context, which is consistent with our hypothesis. Thus, although they perceived girls as the high-status group, both male and female middle-school students reacted to an unfavorable comparison context as high-status group members are expected to do.

However, results did not demonstrate any significant effect of intergroup comparison context or cognitive appraisal on performance. Similar to Study 1, the analysis revealed that boys outperformed girls in terms of general knowledge. The children's version of the Information subtest available in the WISC-IV might therefore carry the same bias as the adult version of the subtest from the WAIS-IV, which most likely interferes in the effect of the 
academic context we intended to observe. Regardless of the induced intergroup comparison context (threatening or not), the idea of being evaluated on stereotypically masculine competence could have negatively impacted girls' performance. Although future studies are needed to investigate the existence and extent of this gender bias, we encourage researchers and practitioners who would use this test to interpret potential gender differences in performance cautiously.

\section{General Discussion}

In two complementary studies, we examined how male and female students appraised and performed in different, potentially stressful, academic contexts, depending on the academic status assigned to their gender group. Our objective was to determine whether girls' relative superior position (compared to boys) on the dimension of academic achievement could prevent them from experiencing social-identity threat in academic context. Indeed, numerous studies have shown that girls are generally more successful than boys at school (e.g., Voyer \& Voyer; 2014). Literature on social-identity threat suggests that, rather than protecting them, girls' highstatus on the dimension of academic achievement could mean they have more to lose than boys if the intergroup comparison becomes unfavorable to them (Scheepers et al., 2009). We therefore hypothesized that an unfavorable context of intergroup comparison on the dimension of academic achievement would have a stronger impact on the performance of students whose gender group is considered to be the high-status group in this dimension. As an indirect manipulation of boys' and girls' academic status, we conducted similar studies at two levels of education supposed to be associated with different status dynamics: high school (Study 1) and middle school (Study 2).

\section{Threat and challenge to gender identity as a function of group status}


As expected, late adolescents (i.e., high-school students) seemed to be aware of girls' better academic achievement in that they attributed them a higher status than boys on the dimension of academic achievement. Although we hypothesized that the youngest adolescents (i.e., middle-school students) would perceive their own gender group as the high-status group because of an ingroup bias in favor of their gender group (e.g., Kurtz-Costes et al., 2014; Verkuyten \& Thijs, 2001), the results showed that they also rated girls' academic status as higher than that of boys. However, despite similar perceptions of boys' and girls' academic status among middle-school and high-school students, the results revealed differences in how these students appraised different academic contexts.

Indeed, gender was more likely to moderate the effect of academic context on perception of threat and challenge to gender identity among high-school, rather than middle-school, students. Male and female middle-school students appraised the outgroup superiority context as more threatening and challenging than the ingroup superiority. Such a result seems to be consistent with Lazarus and Folkman's (1974) who argued that a stressful situation can be perceived as both a threat and a challenge. Among high-school students, in contrast, the effect of the intergroup comparison context was moderated by participants' gender. Although both male and female high-school students perceived the context of outgroup superiority as more threatening to their gender identity than that of ingroup superiority, such a context had more impact on girls' perceived threat. The high status ascribed to girls seemed to lead female highschool students to worry about the risk of losing their academic advantage when facing the possibility of being outperformed by a low-status outgroup on an important exam. At the same time, academic context had a significant impact on boys', but not girls', feeling of challenge to gender identity. Male high-school students perceived the outgroup superiority context as more challenging than the ingroup superiority context, whereas their female counterparts reported a similar, yet high, perception of challenge in the two contexts. Such findings could be related to 
male and female students' awareness of the temporary and very context-specific nature of girls' high status. Indeed, several studies have demonstrated that adolescents, and sometimes children, are aware that men are the high-status group in society (Bigler et al., 2008; Liben et al., 2001; Neff et al., 2007; Teig \& Susskind, 2008). Thus, male high-school students might feel more challenge to their gender identity when the superiority of girls is highlighted if they anticipate a change in gender hierarchy. Future studies are needed to investigate the role of gender hierarchy at a global (i.e., society) level in individuals' reactions to domain-specific status gap.

\section{Developing awareness of gender issues}

We conducted two distinct studies, each corresponding to a level of education (high school and middle school) that we expected to be associated with specific gender dynamics in order to help us distinguish between the effect of gender and the effect of status. Yet, both middle-school and high-school students attributed a higher academic status to girls than to boys on the dimension of academic achievement. Consistent with studies demonstrating that students endorse an academic stereotype favorable to girls from primary school (e.g., Hartley \& Sutton, 2013), students seem to be aware of a gender gap in academic achievement favoring girls, as early as seventh grade. Nevertheless, as described above, different effects of the intergroup comparison context were observed among middle-school and high-school students, in spite of their similar perceptions of boys' and girls' academic status. Consequently, the impact of intergroup comparison context on boys' and girls' feeling of threat and challenge to their social (gender) identity cannot therefore be, at least not entirely, determined by the academic status ascribed to these groups.

Taken together, the present findings instead suggest an interplay between perceived academic status and level of education. Young individuals might develop their awareness and understanding of gender inequalities in a two-step process. In the first step, children or early 
adolescents could become aware of the existence and direction of gender inequalities. The results suggest that middle-school and high-school students have completed this first step as they both attributed a higher academic status to girls than to boys, in line with the observed gender gap in academic achievement (e.g., Voyer \& Voyer, 2014). The second step would refer to the integration of this awareness regarding gender inequalities in the management of the intergroup comparison context, leading to the implementation of different identity-management strategies depending on the relative position of the ingroup. Consistent with this idea, the results showed that no difference between female and male middle-school students in their cognitive appraisal (i.e., perceived threat and challenge) of intergroup comparison contexts, whereas gender differences appeared in high school. The existence of such developmental process, which might not be specific to academic context, remains to be empirically demonstrated. To do so, future research could for instance investigate the coping strategies boys and girls use, depending of their age, to overcome a stressful identity-relevant situation (Berjot \& Gillet, 2011). Such studies would also help determine whether the emergence of gender differences in high-school students' appraisal of intergroup comparison contexts can be explained by a more advanced integration of gender inequality in the implementation of identity-management strategies.

\section{Academic context and students' performance: a biased test?}

Neither Study 1 nor Study 2 demonstrated a significant effect of the intergroup comparison context on performance. This absence of effect might be related to the test we used to measure students' performance, which appears to be one of the main limitations of the present research. Indeed, our results showed that male students in both high school and middle school outperformed female students on the test. These findings are consistent with several studies showing that, although the Information subtest is used to compute the verbal comprehension index, men usually perform better than women (Colom et al., 2002; Daseking et al., 2017; 
Irwing, 2012; van der Sluis et al., 2006). Future studies should investigate how people represent the competence assessed on this subtest, particularly in terms of gender stereotypes. The decision to use this test as our measure of performance was based on the fact that it requires knowledge related to different school subjects, such as literature, science, and history. However, its presentation as a general knowledge test, rather than an academic evaluation, might also be one of the factors contributing to the lack of effect of the intergroup comparison context on performance, as some students might have consequently considered it to be less relevant (i.e., less diagnostic) for academic achievement. Indeed, studies on stereotype threat suggest that the consequences of social-identity threat are limited to the domain in which the threat has been induced (Steele et al., 2002).

\section{Implications and conclusion}

International surveys and research show that girls have better grades than boys in various domains (Pomerantz et al., 2002; Voyer \& Voyer, 2014), are less likely to experience school lag or to drop out of school (Fournier \& Lefresne, 2018; McFarland et al., 2018), and are more likely to enter and graduate from higher education (EURYDICE, 2010; Fiske, 2012; OECD, 2017). It therefore seemed relevant to investigate whether girls' favorable position on the dimension of academic achievement could prevent them from experiencing threat within the school context, especially as the literature concerning high-status groups' experience of social identity threat (e.g., Autin et al., 2014; Scheepers \& Ellemers, 2005; Scheepers et al., 2009) suggests it does not. Although our research showed no significant effect of the intergroup comparison context on students' performance, emphasizing boys' academic success led girls to report more threat to their gender identity (compared to an ingroup superiority context). Consequently, girls' higher academic achievement does not seem to prevent them from experiencing social identity threat on the dimension of academic achievement. These findings could also be interpreted in light of studies showing that, despite their higher academic 
achievement, girls are still discriminated in the school context (Leaper \& Brown, 2014). Girls' intelligence is, for instance, considered to be less malleable than that of boys, and the efforts they put into schoolwork is associated with less potential for future success (Verniers \& Martinot, 2015a). They are also underrepresented in fields in which success is said to require brilliance (Meyer et al., 2015) or intelligence (Verniers \& Martinot, 2015b). Thus, because both female and male high-school students might perceive differences in status between gender groups as unstable and somewhat illegitimate in light of men's and women's position in society, the results observed among these students could be specific to these characteristics of gender status in the school context. Therefore, future studies should explore the role of perceived stability and legitimacy associated with gender status in the school context. Although girls are identified as a high-status group on the dimension of academic achievement, researchers and educators should keep in mind the potential instability of this favorable position.

Data availability statement. The data described in this article are openly available in the Open Science Framework at

\section{https://osf.io/y5bz9/?view only=6e924a939fd94044aa14d71ece8ae8c5}

Funding details. This work was supported by the Auvergne Rhone-Alpes Region under the project INEGS.

Disclosure statement. No potential conflict of interest was reported by the authors.

\section{References}

Adler, N. E., Epel, E. S., Castellazzo, G., \& Ickovics, J. R. (2000). Relationship of subjective and objective social status with psychological and physiological functioning: Preliminary data in healthy white women. Health Psychology, 19(6), 586-592. https://doi.org/10.1037/0278-6133.19.6.586 
Ambady, N., Shih, M., Kim, A., \& Pittinsky, T. L. (2001). Stereotype susceptibility in children: Effects of Identity Activation on Quantitative Performance. Psychological Science, 12(5), 385-390. https://doi.org/10.1111/1467-9280.00371

Autin, F., Branscombe, N. R., \& Croizet, J.-C. (2014). Creating, Closing, and Reversing the Gender Gap in Test Performance: How Selection Policies Trigger Social Identity Threat or Safety Among Women and Men. Psychology of Women Quarterly, 38(3), 327-339. https://doi.org/10.1177/0361684313510485

Berjot, S., \& Gillet, N. (2011). Stress and coping with discrimination and stigmatization. Frontiers in Psychology, 2, 1-13. https://doi.org/10.3389/fpsyg.2011.00033

Berjot, S., Girault-Lidvan, N., \& Gillet, N. (2012). Appraising Stigmatization and Discrimination: Construction and Validation of a Questionnaire Assessing Threat and Challenge Appraisals to Personal and Social Identity. Identity: An International Journal of Theory and Research, 12(3), 191-216. https://doi.org/10.1080/15283488.2012.691254

Bigler, R. S., Arthur, A. E., Hughes, J. M., \& Patterson, M. M. (2008). The politics of race and gender: Children's perceptions of discrimination and the U.S. presidency. Analyses of Social Issues and Public Policy, 8(1), 83-112. https://doi.org/10.1111/j.15302415.2008.00161.x

Blascovich, J. (2008). Challenge and Threat. In A. J. Elliot (Ed.), Handbook of Approach and Avoidance Motivation (pp. 431-445). Psychology Press.

Branscombe, N. R., Schmitt, M. T., \& Harvey, R. D. (1999). Perceiving pervasive discrimination among African Americans: Implications for group identification and wellbeing. Journal of Personality and Social Psychology, 77(1), 135-149. https://doi.org/10.1037/0022-3514.77.1.135 
Chalabaev, A., Major, B., Cury, F., \& Sarrazin, P. (2009). Physiological markers of challenge and threat mediate the effects of performance-based goals on performance. Journal of Experimental Social Psychology, $\quad$ 45(4), 991-994. https://doi.org/10.1016/j.jesp.2009.04.009

Colom, R., García, L. F., Juan-Espinosa, M., \& Abad, F. J. (2002). Sex Differences in General Intelligence: Evidence from the WAIS-III. The Spanish Journal of Psychology, 5(1), 2935.

Cuddy, A. J. C., Fiske, S. T., \& Glick, P. (2008). Warmth and Competence as Universal Dimensions of Social Perception: The Stereotype Content Model and the BIAS Map. Advances in Experimental Social Psychology, 40, 61-149. https://doi.org/10.1016/S00652601(07)00002-0

Daseking, M., Petermann, F., \& Waldmann, H. C. (2017). Sex differences in cognitive abilities: Analyses for the German WAIS-IV. Personality and Individual Differences, 114, 145150. https://doi.org/10.1016/j.paid.2017.04.003

DEPP. (2020). Filles et garçons sur le chemin de l'égalité, de l'école à l'enseignement supérieur. https://doi.org/10.3917/empa.053.0033

Dover, T. L., Major, B., \& Kaiser, C. R. (2016). Members of high-status groups are threatened by pro-diversity organizational messages. Journal of Experimental Social Psychology, 62, 58-67. https://doi.org/10.1016/j.jesp.2015.10.006

Ellemers, N., \& Bos, A. E. R. (1998). Social identity, relative deprivation, and coping with the threat of position loss: A field study among native shopkeepers in Amsterdam. Journal of Applied Social Psychology, 28(21), 1987-2006. https://doi.org/10.1111/j.15591816.1998.tb01357.x 
European Institute for Gender Equality. (2017). Gender Equality Index 2017: Methodological Report. https://doi.org/10.2839/9948

EURYDICE. (2010). Différences entre les genres en matière de réussite scolaire: étude sur les mesures prises et la situation actuelle en Europe. https://doi.org/10.2797/36004

Fiske, E. B. (2012). World Altas of Gender Equality in Education. In UNESCO. https://doi.org/10.15220/978-92-3-104232-4-en

Fiske, S. T., Cuddy, A. J. C., Glick, P., \& Xu, J. (2002). A model of (often mixed) stereotype content: Competence and warmth respectively follow from perceived status and competition. Journal of Personality and Social Psychology, 82(6), 878-902. https://doi.org/10.1037/0022-3514.82.6.878

Fiske, S. T., Dupree, C. H., Nicolas, G., \& Swencionis, J. K. (2016). Status, power, and intergroup relations: The personal is the societal. Current Opinion in Psychology, 11, 44 48. https://doi.org/10.1016/j.copsyc.2016.05.012

Fournier, Y., \& Lefresne, F. (2018). Les inégalités de genre au prisme des objectifs chiffrés de la stratégie européenne Education et Formation 2020. Education \& Formations, 96, 11 38.

Good, C., Aronson, J., \& Harder, J. A. (2008). Problems in the pipeline: Stereotype threat and women's achievement in high-level math courses. Journal of Applied Developmental Psychology, 29(1), 17-28. https://doi.org/10.1016/j.appdev.2007.10.004

Hartley, B. L., \& Sutton, R. M. (2013). A stereotype threat account of boys' academic underachievement. Child Development, 84(5), 1716-1733. https://doi.org/10.1111/cdev.12079

Hayes, A. F. (2013). Introduction to mediation, moderation, and conditional process analysis: 
A regression-based approach. (Guilford publications. (ed.)).

Heyder, A., \& Kessels, U. (2013). Is School Feminine? Implicit Gender Stereotyping of School as a Predictor of Academic Achievement. Sex Roles, 69(11-12), 605-617. https://doi.org/10.1007/s11199-013-0309-9

Heyman, G. D., \& Legare, C. H. (2004). Children's Beliefs About Gender Differences in the Academic and Social Domains. Sex Roles, 50(3/4), 227-239. https://doi.org/10.1023/B:SERS.0000015554.12336.30

Huguet, P., \& Régner, I. (2007). Stereotype Threat Among Schoolgirls in Quasi-Ordinary Classroom Circumstances. Journal of Educational Psychology, 99(3), 545-560. https://doi.org/10.1037/0022-0663.99.3.545

Irwing, P. (2012). Sex differences in g: An analysis of the US standardization sample of the WAIS-III. Personality and Individual Differences, 53(2), 126-131. https://doi.org/10.1016/j.paid.2011.05.001

Koenig, A. M., Eagly, A. H., Mitchell, A. A., \& Ristikari, T. (2011). Are leader stereotypes masculine? A meta-analysis of three research paradigms. Psychological Bulletin, 137(4), 616-642. https://doi.org/10.1037/a0023557

Kurtz-Costes, B., Copping, K. E., Rowley, S. J., \& Kinlaw, C. R. (2014). Gender and Age Differences in Awareness and Endorsement of Gender Stereotypes about Academic Abilities. European Journal of Psychology of Education, 29(4), 603-618. https://doi.org/10.1007/s10212-014-0216-7

Latsch, M., \& Hannover, B. (2014). Smart girls, dumb boys!?: How the discourse on "Failing Boys" Impacts Performances and Motivational Goal Orientation in German School Students. Social Psychology, 45(2), 112-126. https://doi.org/10.1027/1864-9335/a000167 
Lazarus, R. S., \& Folkman, S. (1984). Stress, Appraisal and Coping (Issue c). Springer Publishing Compagny.

Leaper, C., \& Brown, C. S. (2014). Sexism in Schools. In L. S. Liben \& R. S. Bigler (Eds.), Advances in Child Development and Behavior. The role of gender in educational contexts and outcomes (1st ed., Vol. 47, pp. 189-223). Elsevier Inc. https://doi.org/10.1016/bs.acdb.2014.04.001

Liben, L. S., Bigler, R. S., \& Krogh, H. R. (2001). Pink and Blue Collar Jobs: Children's Judgments of Job Status and Job Aspirations in Relation to Sex of Worker. Journal of Experimental Child Psychology, 79(4), 346-363. https://doi.org/10.1006/jecp.2000.2611

Maccoby, E. E. (1987). Gender segregation in childhood. Advances in Child Development and Behavior, 20. https://doi.org/10.1016/S0065-2407(08)60404-8

Major, B., Blodorn, A., \& Major Blascovich, G. (2018). The threat of increasing diversity: Why many White Americans support Trump in the 2016 presidential election. Group Processes and Intergroup Relations, 21(6), 931-940. https://doi.org/10.1177/1368430216677304

Martinot, D., Bagès, C., \& Désert, M. (2012). French Children's Awareness of Gender Stereotypes About Mathematics and Reading: When Girls Improve Their Reputation in Math. Sex Roles, 66(3-4), 210-219. https://doi.org/10.1007/s11199-011-0032-3

Martinot, D., \& Désert, M. (2007). Awareness of a gender stereotype, personal beliefs and selfperceptions regarding math ability: When boys do not surpass girls. Social Psychology of Education, 10(4), 455-471. https://doi.org/10.1007/s11218-007-9028-9

McFarland, J., Cui, J., \& Stark, P. (2018). Trends in High School Dropout and Completion Rates in the United States: 2014. https://nces.ed.gov/pubs2018/2018117.pdf

Meyer, M., Cimpian, A., \& Leslie, S.-J. (2015). Women are underrepresented in fields where 
success is believed to require brilliance. Frontiers in Psychology, 6, 1-12. https://doi.org/10.3389/fpsyg.2015.00235

Neff, K. D., Cooper, C. E., \& Woodruff, A. L. (2007). Children's and adolescents' developing perceptions of gender inequality. Social Development, 16(4), 682-699. https://doi.org/10.1111/j.1467-9507.2007.00411.x

Neuville, E., \& Croizet, J. C. (2007). Can salience of gender identity impair math performance among 7-8 years old girls? The moderating role of task difficulty. European Journal of Psychology of Education, 22(3), 307-316. https://doi.org/10.1007/BF03173428

Nowicki, E. A., \& Lopata, J. (2015). Children's implicit and explicit gender stereotypes about mathematics and reading ability. Social Psychology of Education, 20(2), 329-345. https://doi.org/10.1007/s11218-015-9313-y

OECD. (2013). PISA 2012 Results: Ready to Learn (Volume III). https://doi.org/10.1787/9789264201170-en

OECD. (2015). The ABC of Gender Equality in Education. OECD Publishing. https://doi.org/10.1787/9789264229945-en

OECD. (2017). Education at a Glance 2017: OECD Indicators. OECD Publishing. https://doi.org/http://dx.doi.org/10.1787/eag-2017-en

Pansu, P., Régner, I., Max, S., Colé, P., Nezlek, J. B., \& Huguet, P. (2016). A burden for the boys: Evidence of stereotype threat in boys' reading performance. Journal of Experimental Social Psychology, 65, 26-30. https://doi.org/10.1016/j.jesp.2016.02.008

Passolunghi, M. C., Rueda Ferreira, T. I., \& Tomasetto, C. (2014). Math-gender stereotypes and math-related beliefs in childhood and early adolescence. Learning and Individual Differences, 34, 70-76. https://doi.org/10.1016/j.lindif.2014.05.005 
Pomerantz, E. M., Altermatt, E. R., \& Saxon, J. L. (2002). Making the grade but feeling distressed: Gender differences in academic performance and internal distress. Journal of Educational Psychology, 94(2), 396-404. https://doi.org/10.1037/0022-0663.94.2.396

Powlishta, K. K. (1995). Gender bias in children's perceptions of personality traits. Sex Roles, 32(1-2), 17-28. https://doi.org/10.1007/BF01544755

Regner, I., Steele, J. R., Ambady, N., Thinus-Blanc, C., \& Huguet, P. (2014). Our future scientists: A review of stereotype threat in girls from early\nelementary school to middle school. International Review of Social Psychology, 27(3-4), 13-51. https://doi.org/10.1088/0022-3719/18/6/023

Robnett, R. D., \& Susskind, J. E. (2010). Who Cares About Being Gentle? The Impact of Social Identity and the Gender of One's Friends on Children's Display of Same-Gender Favoritism. Sex Roles, 63(11), 820-832. https://doi.org/10.1007/s11199-010-9843-x

Rucker, D. D., Preacher, K. J., Tormala, Z. L., \& Petty, R. E. (2011). Mediation analysis in social psychology: Current practices and new recommendations. Social and Personality Psychology Compass, 5(6), 359-371.

Ruggiero, K. M., \& Major, B. (1998). Group Status and Attribution to Discrimination: Are Low or High-Status Group Members More Likely to Blame Their Failure on Discrimination. Personality \& Social Psychology Bulletin, 24(8), 821-837.

Ruggiero, K. M., \& Taylor, D. M. (1997). Why Minority Group Members Perceive or Do Not Perceive the Discrimination That Confronts Them: The Role of Self-Esteem and Perceived Control. Journal of Personality and Social Psychology, 72(2), 373-389. https://doi.org/10.1037/0022-3514.72.2.373

Sachdev, I., \& Bourhis, R. Y. (1987). Status differenttals and intergroup behaviour. European 
Journal of Social Psychology, 17(3), 277-293. https://doi.org/10.1002/ejsp.2420170304

Scheepers, D. (2017). Intergroup status differences as challenge or threat: The role of legitimacy. Group Processes and Intergroup Relations, 20(1), 75-90. https://doi.org/10.1177/1368430215595108

Scheepers, D., \& Ellemers, N. (2005). When the pressure is up: The assessment of social identity threat in low and high status groups. Journal of Experimental Social Psychology, 4l(2), 192-200. https://doi.org/10.1016/j.jesp.2004.06.002

Scheepers, D., Ellemers, N., \& Sintemaartensdijk, N. (2009). Suffering from the possibility of status loss: physiological responses to social identity threat in high status groups. European Journal of Social Psychology, 39, 1075-1092. https://doi.org/10.1002/ejsp

Schmitt, M. T., \& Branscombe, N. R. (2002). The Meaning and Consequences of Perceived Discrimination in Disadvantaged and Privileged Social Groups. European Review of Social Psychology, 12(1), 167-199. https://doi.org/10.1080/14792772143000058

Seery, M. D., Weisbuch, M., Hetenyi, M. A., \& Blascovich, J. (2010). Cardiovascular measures independently predict performance in a university course. Psychophysiology, 47(3), 535539. https://doi.org/10.1111/j.1469-8986.2009.00945.x

Skinner, N., \& Brewer, N. (2002). The dynamics of threat and challenge appraisals prior to stressful achievement events. Journal of Personality and Social Psychology, 83(3), 678692. https://doi.org/10.1037/0022-3514.83.3.678

Spencer, S. J., Logel, C., \& Davies, P. G. (2016). Stereotype threat. Annual Review of Psychology, 67, 415-437. https://doi.org/10.4324/9780203361993

Spencer, S. J., Steele, C. M., \& Quinn, D. M. (1999). Stereotype Threat and Women's Math Performance. Journal of Experimental Social Psychology, 35, 4-28. 
Steele, C. M., Spencer, S. J., \& Aronson, J. (2002). Contending with group image: The psychology of stereotype and social identity threat. Advances in Experimental Social Psychology, 34, 379-440. https://doi.org/10.1016/S0065-2601(02)80009-0

Stephan, W. G., Ybarra, O., \& Morrison, K. R. (2009). Intergroup Threat Theory. In T. D. Nelson (Ed.), Handbook of Prejudice, Stereotyping and Discrimination (pp. 43-60). Psychological Press.

Susskind, J. E., \& Hodges, C. (2007). Decoupling children's gender-based in-group positivity from out-group negativity. Sex Roles, 56(11-12), 707-716. https://doi.org/10.1007/s11199-007-9235-z

Sweeting, H., West, P., Young, R., \& Kelly, S. (2011). Dimensions of adolescent subjective social status within the school community: Description and correlates. Journal of Adolescence, 34(3), 493-504. https://doi.org/10.1016/j.adolescence.2010.06.001

Tajfel, H., \& Turner, J. C. (1979). An Integrative Theory of Intergroup Conflict. In W. G. Austin \& S. Worchel (Eds.), The Social Psychology of Intergroup Relations (pp. 56-65). BrooksCole. https://doi.org/10.1016/S0065-2601(05)37005-5

Teig, S., \& Susskind, J. E. (2008). Truck driver or nurse? the impact of gender roles and occupational status on children's occupational preferences. Sex Roles, 58(11-12), 848863. https://doi.org/10.1007/s11199-008-9410-X

Tomasetto, C., Alparone, F. R., \& Cadinu, M. (2011). Girls' Math Performance Under Stereotype Threat: The Moderating Role of Mothers' Gender Stereotypes. Developmental Psychology, 47(4), 943-949. https://doi.org/10.1037/a0024047

van der Sluis, S., Posthuma, D., Dolan, C. V., de Geus, E. J. C., Colom, R., \& Boomsma, D. I. (2006). Sex differences on the Dutch WAIS-III. Intelligence, 34(3), 273-289. 
https://doi.org/10.1016/j.intell.2005.08.002

Verkuyten, M., \& Thijs, J. (2001). Ethnic and Gender Bias among Dutch and Turkish Children in Late Childhood: The Role of Social Context. Infant and Child Development, 10(4), 203217. https://doi.org/10.1002/icd.279

Verniers, C., \& Martinot, D. (2015a). Characteristics expected in fields of higher education and gender stereotypical traits related to academic success: a mirror effect. Social Psychology of Education, 18(4), 719-733. https://doi.org/10.1007/s11218-015-9312-z

Verniers, C., \& Martinot, D. (2015b). Perception of students' intelligence malleability and potential for future success: Unfavourable beliefs towards girls. British Journal of Educational Psychology, 85(3), 289-299. https://doi.org/10.1111/bjep.12073

Vick, S. B., Seery, M. D., Blascovich, J., \& Weisbuch, M. (2008). The effect of gender stereotype activation on challenge and threat motivational states. Journal of Experimental Social Psychology, 44(3), 624-630. https://doi.org/10.1016/j.jesp.2007.02.007

Voyer, D., \& Voyer, S. D. (2014). Psychological Bulletin Gender Differences in Scholastic Achievement: A Gender Differences in Scholastic Achievement: A Meta-Analysis. Psychological Bulletin, 140(4), 1174 - 1204. https://doi.org/10.1037/a0036620

Yee, M., \& Brown, R. (1994). The development of gender differentiation in young children. British Journal of Social Psychology, 33(2), 183-196. https://doi.org/10.1111/j.20448309.1994.tb01017.x

Yzerbyt, V. (2016). Intergroup stereotyping. Current Opinion in Psychology, 11, 90-95. https://doi.org/10.1016/j.copsyc.2016.06.009 
Table 1

Means, standard deviations and correlations between variables (study 1).

\begin{tabular}{lllllll}
\hline & 2 & 3 & 4 & 5 & $\mathrm{M}$ & $\mathrm{SD}$ \\
\hline 1. Academic status attributed to boys & $.58^{* *}$ & -.07 & -.05 & $.15^{*}$ & 7.37 & 1.13 \\
2. Academic status attributed to girls & & -.01 & .08 & .05 & 8.09 & 1.13 \\
3. Threat to gender identity & & & $.45^{* *}$ & -.05 & 1.92 & 1.25 \\
4. Challenge to gender identity & & & & $-.16^{*}$ & 3.83 & 1.95 \\
5. Performance & & & & & 10.45 & 2.95 \\
\hline
\end{tabular}

Note. ${ }^{*} p<.05, * * p<.001 . \mathrm{M}=$ mean, $\mathrm{SD}=$ standard deviation. 
Table $2 \mathrm{a}$

Summary of moderated mediation analysis with threat as the mediator (Study 1).

\begin{tabular}{lccccc}
\hline \multicolumn{7}{c}{ Coefficient } & SE & $\mathbf{t}$ & $\mathbf{p}$ & $\mathbf{9 5 \% C I}$ \\
\hline \multicolumn{7}{l}{ Outcome variable: } & Threat to gender & identity & & & \\
\hline Constant & 0.03 & 0.08 & 0.34 & .74 & {$[-0.14,0.19]$} \\
Context & 1.01 & 0.17 & 6,01 & .00 & {$[0.68,1.34]$} \\
Gender & 0.16 & 0.17 & 0.96 & .34 & {$[-0.17,0.49]$} \\
Context x Gender & 0.55 & 0.34 & 1.64 & .10 & {$[-0.11,1.21]$} \\
Grade average & -0.02 & 0.03 & -0.57 & .57 & {$[-0.08,0.04]$} \\
\hline Outcome variable : Performance & & & & \\
\hline Constant & 10.31 & 0.18 & 57.42 & .00 & {$[9.96,10.66]$} \\
Context & -0.47 & 0.40 & -1.18 & .24 & {$[-1.25,0.31]$} \\
Threat & 0.05 & 0.16 & 0.33 & .74 & {$[-0.26,0.36]$} \\
Gender & -1.62 & 0.36 & -4.50 & .00 & {$[-2.33,-0.91]$} \\
Context x Gender & 0.15 & 0.79 & 0.19 & .85 & {$[-1.42,1.72]$} \\
Threat x Gender & -0.16 & 0.32 & -0.50 & .62 & {$[-0.78,0.47]$} \\
Grade average & 0.55 & 0.07 & 8.08 & .00 & {$[0.41,0.68]$} \\
\hline Moderated mediation index & & & & \\
\hline \multicolumn{7}{l}{ Conditional indirect effects of context on performance } & & {$[-0.68,0.56]$} \\
\hline Boys & 0.10 & 0.15 & & \\
Girls & -0.03 & 0.28 & & {$[-0.22,0.41]$} \\
\hline
\end{tabular}

Note. $\mathrm{SE}=$ standard error, $\mathrm{CI}=$ Confidence Interval. 
Table $2 b$

Summary of moderated mediation analysis with challenge as the mediator (Study 1).

\begin{tabular}{lccccc}
\hline \multicolumn{7}{c}{ Coefficient } & SE & t & P & 95\%CI \\
\hline Outcome variable: Challenge to gender & identity & & & \\
\hline Constant & 0.09 & 0.13 & 0.66 & .51 & {$[-0.18,0.35]$} \\
Context & 0.89 & 0.27 & 3.34 & .00 & {$[0.36,1.42]$} \\
Gender & 0.73 & 0.27 & 2.74 & .01 & {$[0.21,1.26]$} \\
Context x Gender & -1.30 & 0.54 & -2.42 & .02 & {$[-2.36,-0.24]$} \\
Grade average & 0.01 & 0.05 & 0.19 & .85 & {$[-0.09,0.11]$} \\
\hline Outcome variable: Performance & & & & \\
\hline Constant & 10.31 & 0.18 & 56.68 & .00 & {$[9.95,10.67]$} \\
Context & -0.28 & 0.37 & -0.75 & .45 & {$[-1.01,0.45]$} \\
Challenge & -0.16 & 0.10 & -1.62 & .11 & {$[-0.35,0.03]$} \\
Gender & -1.54 & 0.36 & $-4,22$ & .00 & {$[-2.26,-0.82]$} \\
Context x Gender & -0.02 & 0.74 & -0.02 & .98 & {$[-1.48,1.45]$} \\
Challenge x Gender & -0.08 & 0.20 & -0.42 & .68 & {$[-0.47,0.30]$} \\
Grade average & 0.54 & 0.07 & 8.08 & .00 & {$[0.41,0.68]$} \\
\hline Moderated mediation index & & & & {$[-0.32,0.63]$} \\
\hline \multicolumn{7}{l}{ Conditional indirect effects of context on performance } & & & \\
\hline Boys & -0.18 & 0.21 & & & {$[-0.26,0.16]$} \\
\hline Girls & -0.05 & 0.10 & & & \\
\hline
\end{tabular}


Table 3

Means, standard deviations and correlations between variables (study 2).

\begin{tabular}{llccccc}
\hline & 2 & 3 & 4 & 5 & $\mathrm{M}$ & $\mathrm{SD}$ \\
\hline 1. Academic status attributed to boys & $.42^{* *}$ & -.06 & -.01 & $.14^{*}$ & 6.81 & 1.41 \\
2. Academic status attributed to girls & & -.02 & .08 & .09 & 8.02 & 1.05 \\
3. Threat to gender identity & & & $.48^{* *}$ & -.10 & 2.99 & 1.55 \\
4. Challenge to gender identity & & & & $-.14^{*}$ & 4.77 & 1.63 \\
5. Performance & & & & & 11.31 & 2.91 \\
\hline
\end{tabular}

Note. ${ }^{*} p<.05, * * p<.001 . \mathrm{M}=$ mean, $\mathrm{SD}=$ standard deviation. 
Table 4a

Summary of moderated mediation analysis with threat as the mediator (Study 2).

\begin{tabular}{lccccc}
\hline \multicolumn{7}{c}{ Coefficient } & SE & $\mathbf{t}$ & $\mathbf{p}$ & $\mathbf{9 5 \% C I}$ \\
\hline \multicolumn{7}{l}{ Outcome variable: } & Threat to gender identity & & & \\
\hline Constant & -0.01 & 0.10 & -0.10 & .92 & {$[-0.21,0.19]$} \\
Context & 0.95 & 0.20 & 4.78 & .00 & {$[0.56,1.35]$} \\
Gender & 0.47 & 0.20 & 2.36 & .02 & {$[0.08,0.86]$} \\
Context x Gender & 0.14 & 0.40 & 0.35 & .72 & {$[-0.64,0.92]$} \\
Grade average & -0.05 & 0.53 & -1.04 & .30 & {$[-0.14,0.04]$} \\
\hline Outcome variable : Performance & & & & \\
\hline Constant & 11.40 & 0.18 & 64.02 & .00 & {$[11.05,11.75]$} \\
Context & -0.38 & 0.37 & 1.02 & .31 & {$[-0.36,1.11]$} \\
Threat & -0.05 & 0.12 & -0.42 & .68 & {$[-0.29,0.19]$} \\
Gender & -1.24 & 0.36 & -3.49 & .00 & {$[-1,95,-0.54]$} \\
Context x Gender & -0.38 & 0.74 & -0.51 & .61 & {$[-1.84,1.08]$} \\
Threat x Gender & -0.40 & 0.24 & -1.63 & .10 & {$[-0.88,0.08]$} \\
Grade average & 0.58 & 0.08 & 7.24 & .00 & {$[0.42,0.74]$} \\
\hline Moderated mediation index & & & & \\
\hline \multicolumn{7}{l}{ Conditional indirect effects of context on performance } & & {$[-0.94,0.13]$} \\
\hline Boys & 0.13 & 0.22 & & {$[-0.29,0.59]$} \\
Girls & -0.26 & 0.17 & & & \\
\hline
\end{tabular}


Table 4b

Summary of moderated mediation analysis with challenge as the mediator (Study 2).

\begin{tabular}{lccccc}
\hline \multicolumn{1}{c}{ Coefficient } & SE & $\mathbf{t}$ & $\mathbf{P}$ & $\mathbf{9 5 \% C I}$ \\
\hline Outcome variable: Challenge to gender & identity & & & \\
\hline Constant & 0.01 & 0.11 & 0.10 & .02 & {$[-0.20,0.23]$} \\
Context & 0.45 & 0.22 & 2.04 & .04 & {$[0.02,0.89]$} \\
Gender & 0.03 & 0.22 & 0.13 & .89 & {$[-0.40,0.46]$} \\
Context x Gender & 0.45 & 0.44 & 1.03 & .30 & {$[-0.41,1.32]$} \\
Grade average & -0.06 & 0.05 & -1.31 & .19 & {$[-0.16,0.03]$} \\
\hline Outcome variable: Performance & & & & \\
\hline Constant & 11.35 & 0.18 & 64.70 & .00 & {$[11.01,11.70]$} \\
Context & 0.43 & 0.36 & 1.19 & .24 & {$[-0.28,1.13]$} \\
Challenge & -0.17 & 0.11 & -1.55 & .12 & {$[-0.38,0.05]$} \\
Gender & -1.23 & 0.35 & -3.58 & .00 & {$[-1.95,-0.57]$} \\
Context x Gender & -0.59 & 0.71 & -0.83 & .41 & {$[-1.99,0.81]$} \\
Challenge x Gender & -0.23 & 0.22 & -1.09 & .28 & {$[-0.66,0.19]$} \\
Grade average & 0.58 & 0.08 & 7.30 & .00 & {$[0.43,0.74]$} \\
\hline Moderated mediation index & -0.18 & 0.16 & & & {$[-0.52,0.13]$} \\
\hline \multicolumn{7}{l}{ Conditional indirect effects of context on performance } & & & {$[-0.25,0.16]$} \\
\hline Boys & -0.01 & 0.09 & & & {$[-0.51,0.02]$} \\
\hline Girls & -0.19 & 0.14 & &
\end{tabular}


Figure 1. Moderated mediation models representing the theoretical hypotheses

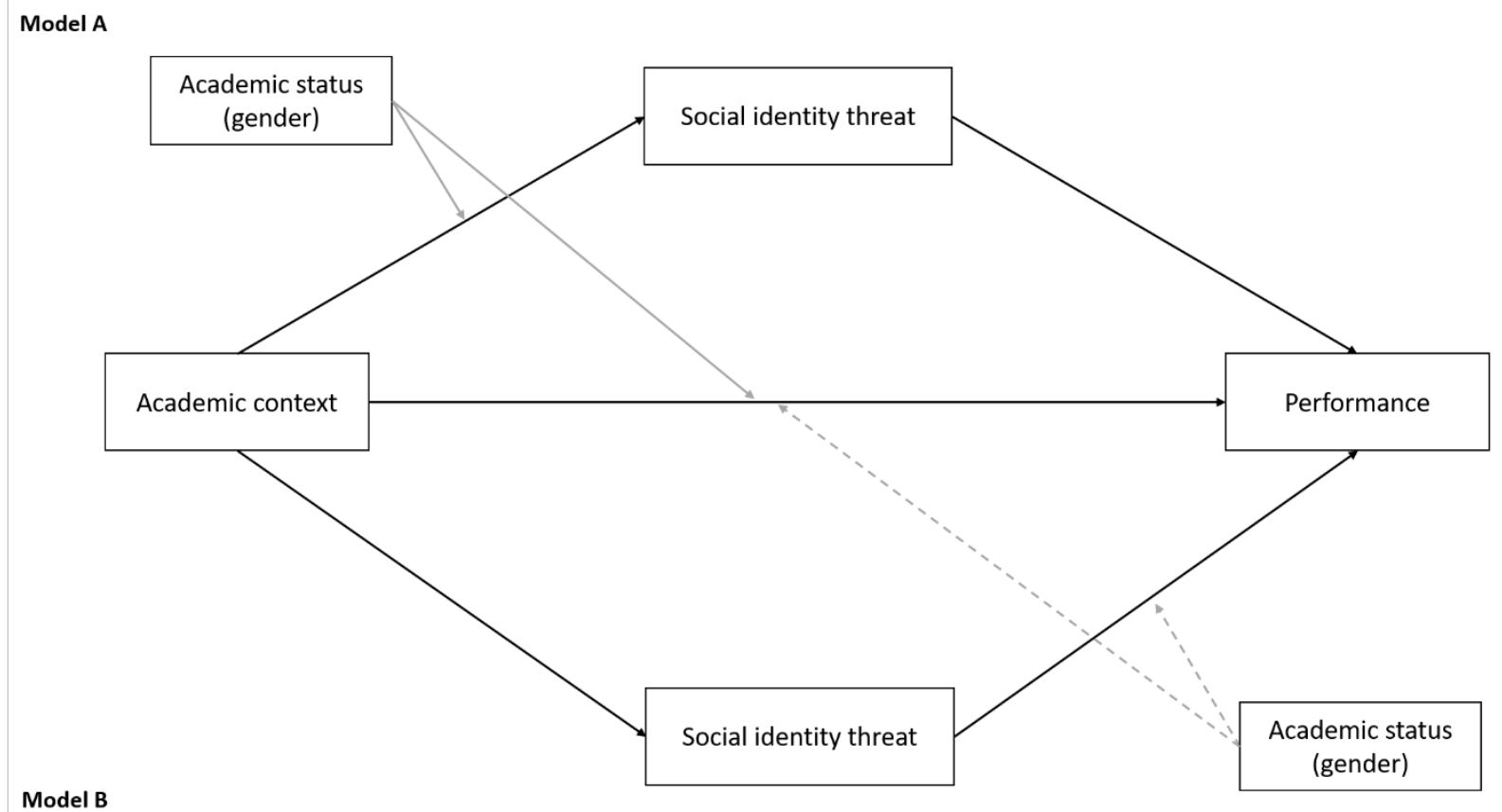

Figure 2. Perceived threat and challenge to social identity (Study 1)

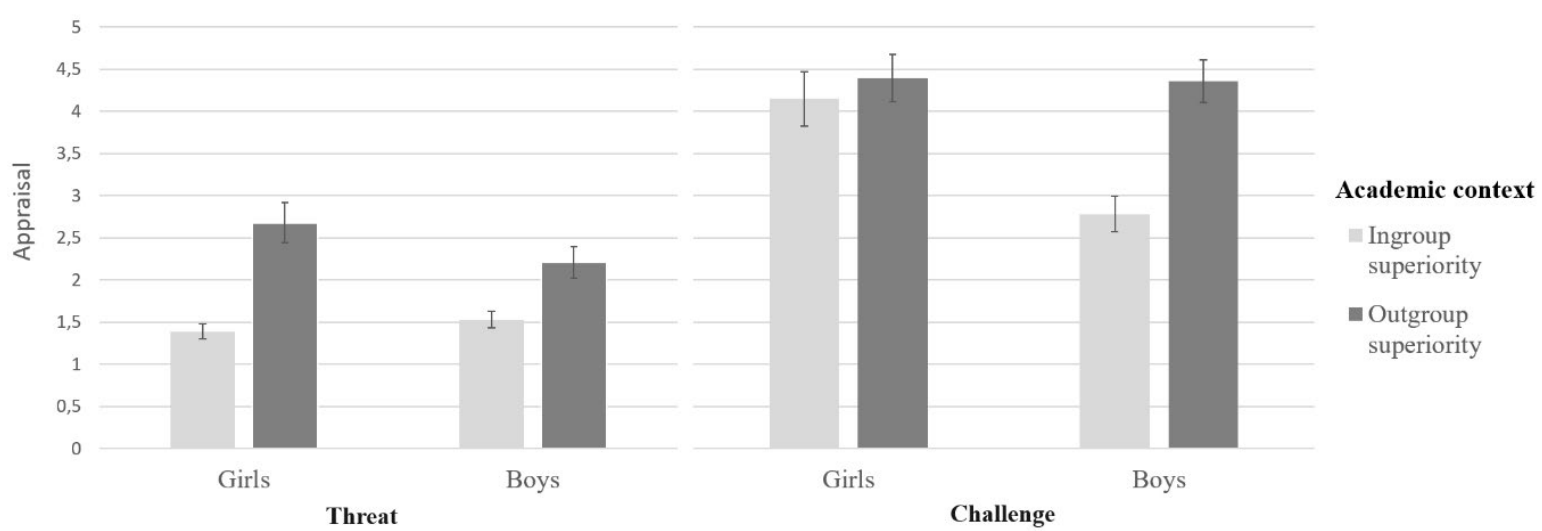

